\title{
Algunas imágenes del sincretismo simbólico y religioso al interior del Carnaval del Perdón
}

Some images of symbolic and religious syncretism within the Carnaval del Perdón

\section{REsUMEN}

El presente ensayo fotográfico expone algunas representaciones culturales del festival Clëstrinye o Bëtscnaté (Carnaval del Perdón o el Día Grande) celebrado en el Valle del Sibundoy. Desde una perspectiva analítica y basada en relatos recolectados en campo, estas imágenes relacionan las diversas lógicas de aculturamiento y modificación sociocultural que trajo consigo la misión capuchina a finales del siglo XIX e inicio del XX en el Putumayo (Colombia). De este modo, se observa el Carnaval del Perdón desde un sincretismo simbólico, cultural y religioso que ha perdurado durante décadas en la parte más andina de este departamento.

Palabras clave: Valle del Sibundoy, Carnaval del Perdón, Comunidad Indígena Inga, Comunidad Indígena Camëtsa, Sincretismo Simbólico, Misión Capuchina.

\section{Abstract}

This photographic essay shows some cultural representations of the Clëstrinye or Bëtscnaté festival (Carnival of Forgiveness or the Big Day) celebrated in the Sibundoy Valley. From an analytical perspective based on stories collected in the field, these images relate the various logics of acculturation and sociocultural modification

\author{
Alen Castaño \\ Instituto de Estudios \\ Interculturales de la Pontificia \\ Universidad Javeriana \\ de Cali. Colombia. \\ $\square$ alencastano@gmail.com / \\ alencastano@yahoo.com \\ (D. ORCID: 0000-0003-2803-8839 \\ $\checkmark$ Google Scholar
}

Dedicado in memoriam a Jakoshin Herlly. Fuerza y energía a Pedro y a toda la familia Jajoy (Colón, Putumayo) 
that the Capuchin mission brought about in Putumayo (Colombia) in the late 19th and early 20th centuries. This article observes the Carnaval del Perdón through the symbolic, cultural and religious syncretism that has lasted for decades in the Andean region of this department.

Keywords: Sibundoy Valley, Forgiveness Carnival, Inga Indigenous Community, Camëtsa Indigenous Community, Symbolic Syncretism, Capuchin Mission.

$\mathrm{D}$ os días antes del miércoles de ceniza se realiza anualmente en el Valle de Sibundoy (Alto Putumayo - Colombia) el Carnaval del Perdón, Clëstrinye o Bëtscnaté (Fajardo, 2006). Una festividad cargada de simbolismos y significaciones producto de la interacción histórica entre dos mundos: el occidental y el indígena. La perspectiva occidental es evidenciada mediante el paradigma eclesiástico, en este caso, desde la misión capuchina establecida en el Putumayo (Colombia) a finales del siglo XIX e inicios del XX. Por su parte, la perspectiva indígena es representada a través de la concepción cultural de las comunidades Inga y Camëtsa que históricamente han residido en la parte alta de este departamento.

Teniendo en cuenta las generalidades anteriores, las siguientes imágenes presentan algunas expresiones culturales de este carnaval, que, desde una perspectiva analítica y basada en relatos recolectados en campo, evidencian lógicas de aculturamiento y modificación sociocultural que trajo consigo la interacción de perspectivas dadas entre la misión capuchina establecida en este lugar de la geografía colombiana y la cosmovisión indígena andina (Bonilla, 1968).

Cabe resaltar que esta festividad étnica fue reacomodada de acuerdo al calendario católico impuesto por las lógicas coloniales y evangelizadoras capuchinas en la región, para que estas puedan ser celebradas antes de la cuaresma (Jaramillo Guerrero y Dávila Zambrano, 2013). A pesar de la carga simbólica y las representaciones de aculturamiento que pueden ser identificadas en este carnaval, actualmente el Bëtscnaté está catalogado como un patrimonio cultural inmaterial del ámbito nacional, dado que es una manifestación histórica, identitaria y cultural de las comunidades indígenas Camëtsa e Inga del departamento del Putumayo (Resolución No. 3471 de 2013). 
Para poder ilustrar los diferentes aspectos simbólicos que expresan tal sincretismo religioso y cultural entre dos cosmovisiones completamente diferentes que han convivido durante siglos en la región del Alto Putumayo, se expondrán diversos segmentos que constituyen este carnaval. Así mismo, es necesario recalcar que el presente registro fotográfico hizo parte de diversos ejercicios etnográficos realizados durante tres años de visita al Valle de Sibundoy. A partir de tres inmersiones a esta región, debido a un proyecto liderado y fomentado por el programa de Antropología de la Universidad ICESI (Cali) denominado Laboratorio Etnográfico, se pudo adentrar, dialogar, observar y participar, no sólo al interior de este carnaval, sino que también en múltiples reuniones, sesiones y diálogos que permitieron adentrarse en las diversas concepciones que giran alrededor de las cosmovisiones de las comunidades Inga y Camëtsa que residen en este valle.

Por tal motivo, se debe remarcar que este texto se convierte en un registro de imágenes que condensan una pequeña expresión simbólica y cultural de la comunidad indígena Inga y Camëtsa del Valle del Sibundoy a través de fotografías, vivencias, diálogos con la comunidad y soportes de fuentes secundarias que han tratado directa e indirectamente este tema.

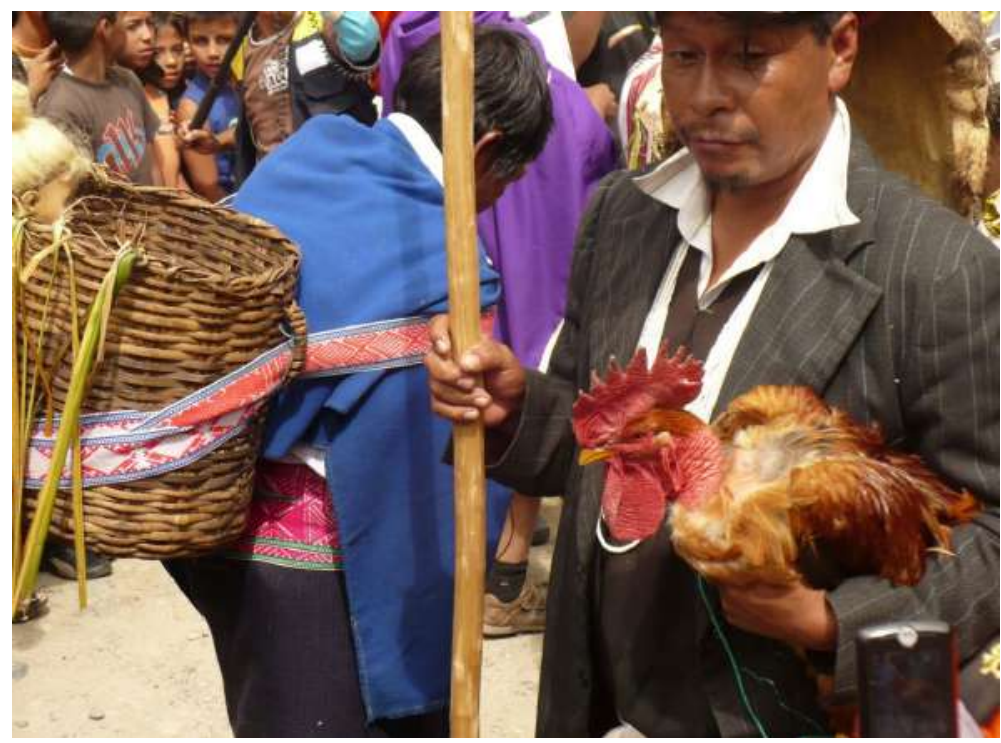

Figura 1. El Carnaval del Perdón.

Fuente: Fotografía de Alen Castaño. Sibundoy. 2009. 


\section{¿El Carnaval del Perdón?}

El primer aspecto a resaltar es el nombre en sí del carnaval (Figura 1). Quienes hemos podido estar en su interior, observamos cómo diversas personas de la comunidad van donde los mayores a pedirle consejos; algunas otras van donde conocidos a pedirles disculpas si tuvo algún altercado o inconveniente con éstos en el año inmediatamente pasado (Figura 2). De este modo, la práctica que se realiza en su interior no reside en pedir perdón, sino pedir un consejo en un día de regocijo para compartir en un nuevo año que empieza; donde se planea el futuro para seguir viviendo armónicamente al interior de la comunidad (Jaramillo Guerrero y Dávila Zambrano, 2013).

A partir de la interacción con diversas personas Camëtsa durante esta celebración, se pudo constatar la consolidación de una hipótesis al interior de la comunidad local (más que todo la colona y la extranjera) al afirmar que el nombre del carnaval nace de este tipo de acciones reivindicativas entre las personas que participan en este ritual, las cuales fueron percibidas por la visión eclesiástica occidental como aquel feligrés que va ante el cura a confesarle y pedir redención por sus acciones (Fajardo, 2006).

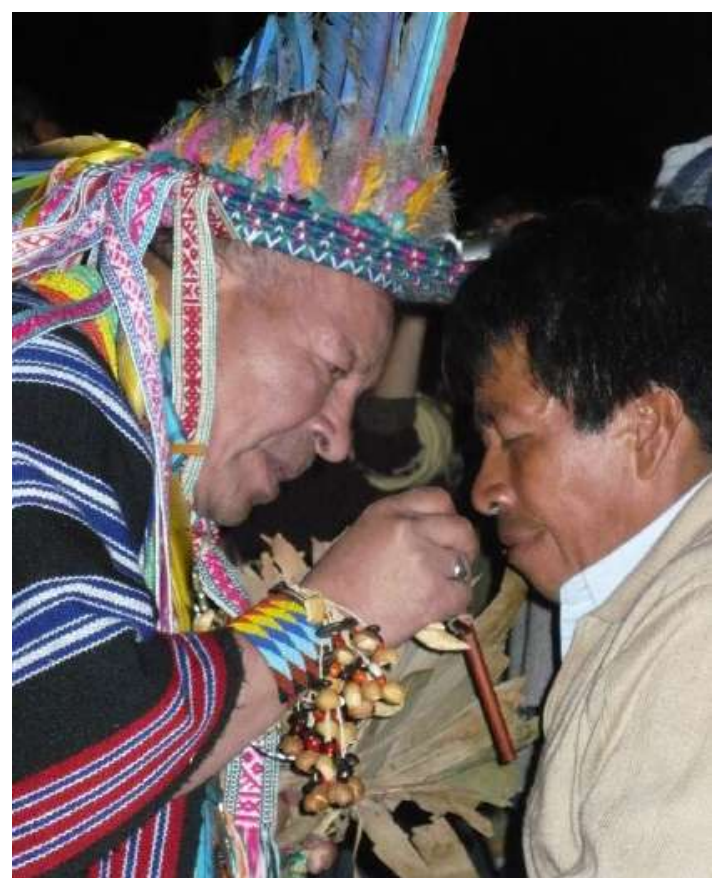

Figura 2. ¿Consejo, reconciliación o perdón?

Fuente: Fotografía de Alen Castaño. Sibundoy. 2009. 


\section{La construcción y representación del Castillo}

Otra connotación occidental identificada en esta expresión cultural es la del Castillo, uno de los símbolos más emblemáticos del carnaval (Figura 3). Este es un armazón de árboles, entretejido con hojas de palma que sirven de estera para la construcción en la parte superior de esta estructura (Gómez Montañez, 2017). Es aquí donde se realiza el sacrificio del gallo. Animal que es utilizado en este carnaval por parte de las comunidades indígenas Camëtsa e Inga como una representación del tiempo, marcando el inicio y fin de cada año (Fajardo, 2006).

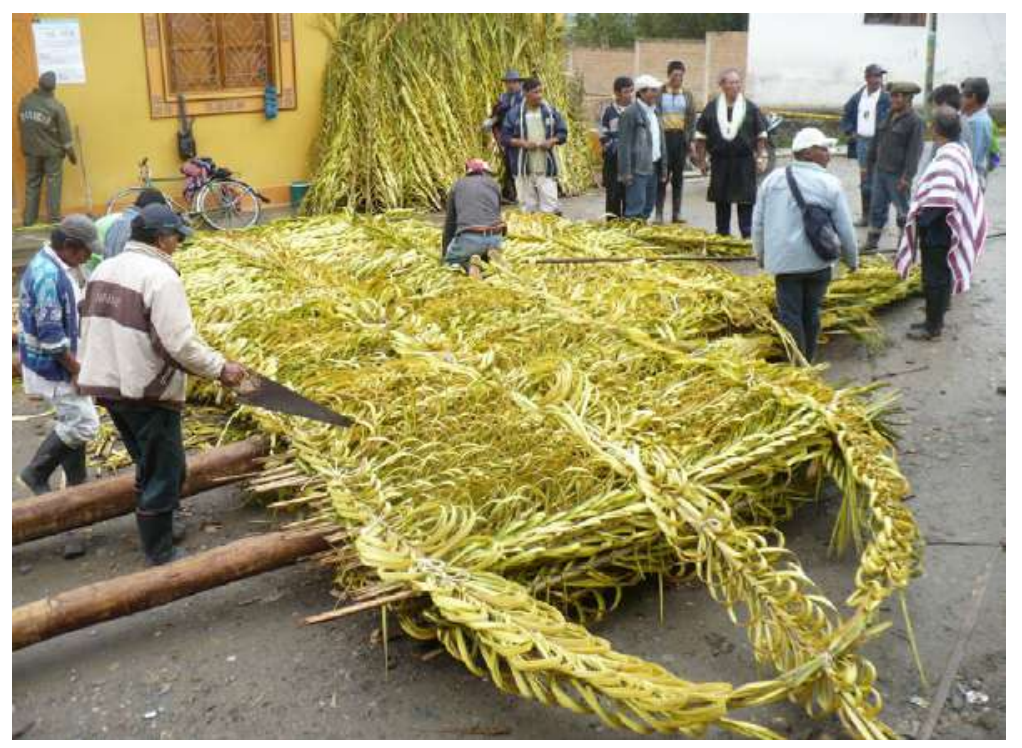

Figura 3. El Castillo.

Fuente: Fotografía de Alen Castaño. Sibundoy. 2009.

\section{Caminando de la mano: el Matachín y la Virgen del Carmen}

Antes de iniciar el carnaval, a las afueras del pueblo todos los personajes de este carnaval se alistan en sus respectivas casas, las cuales se convierten en espacios de encuentro, diálogo y expresión de cada protagonista e integrante de esta festividad (Figura 4). Es desde cada uno de estos puntos donde salen los personajes principales a la vía que conduce al centro poblado, confluyendo cada elemento del carnaval de manera a priori en aquella carretera que guía la festividad hacia el castillo (Jaramillo Guerrero y Dávila Zambrano, 2013). Esta conglomeración de personajes es liderada por el Matachín, figura emblemática del carnaval que se encarga de guiarlo desde su inicio hasta el final (Figura 5). 


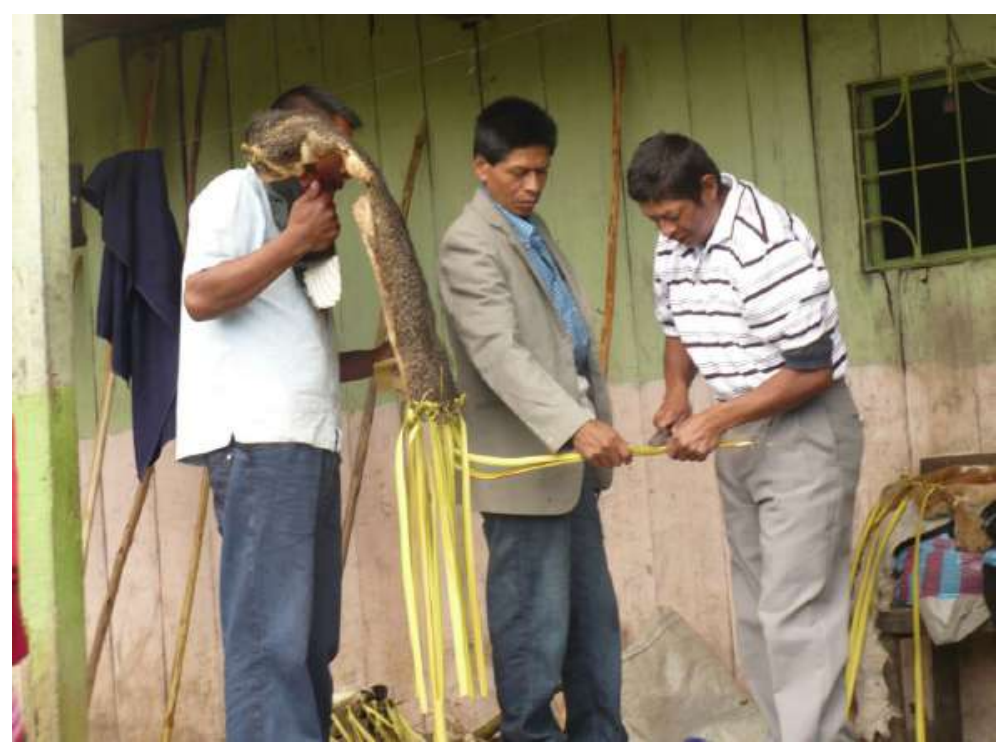

Figura 4. La preparación.

Fuente: Fotografía de Alen Castaño. Sibundoy. 2009.

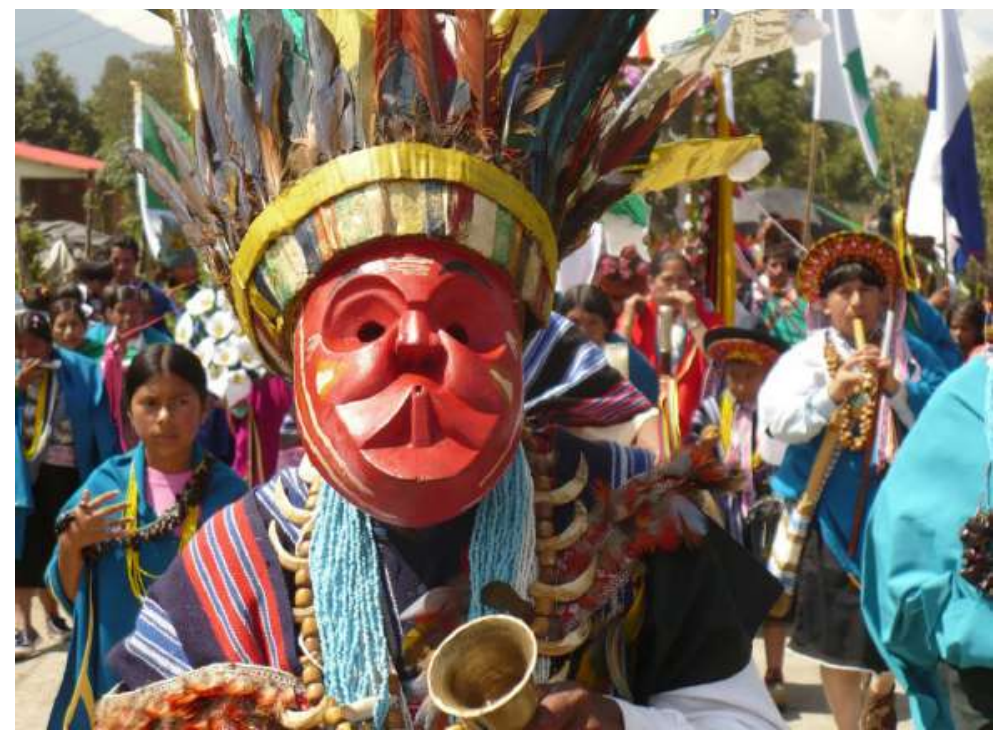

Figura 5. El Matachín.

Fuente: Fotografía de Alen Castaño. Sibundoy. 2009.

Durante esta caminata hacia el centro poblado resalta la figura de la Virgen del Carmen, la cual es cargada por mujeres durante la procesión que culmina en la iglesia del pueblo (Figura 6). Una representación andina referente a los largos viajes que realizaban los indígenas en la época colonial y al vínculo que tiene la feminidad con la madre tierra (Pulido Ángel, 2015). 


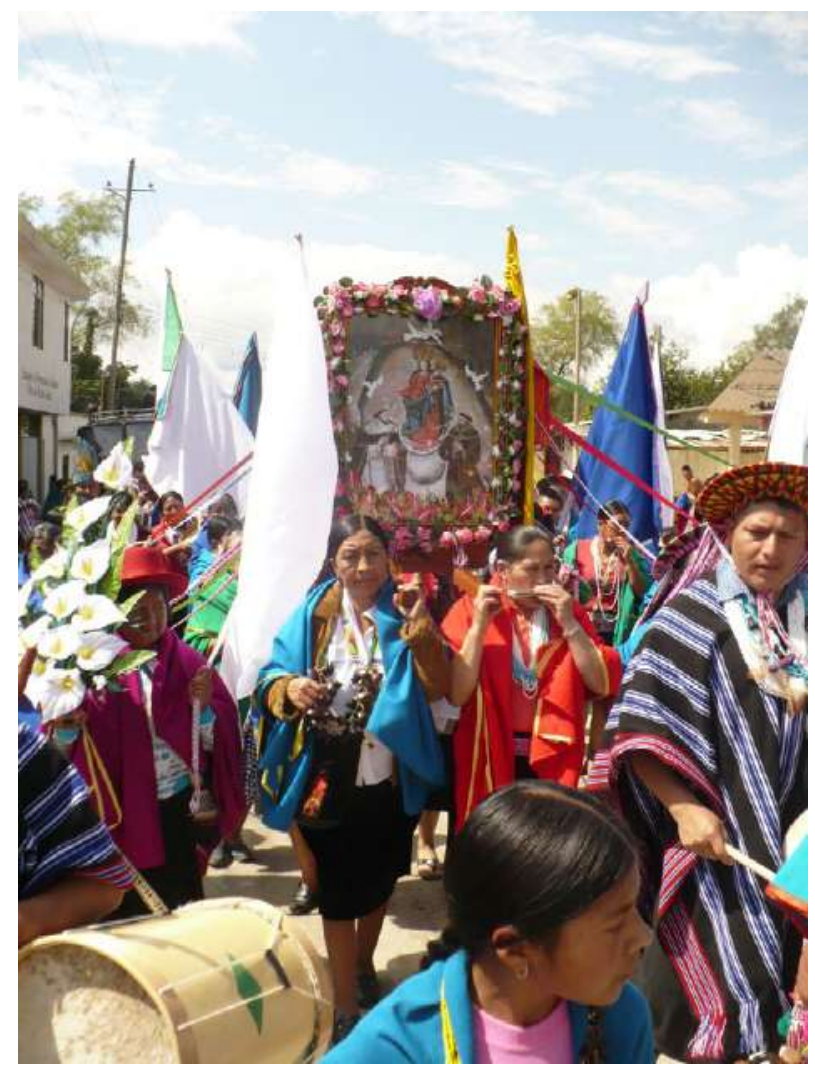

Figura 6. La Virgen del Carmen.

Fuente: Fotografía de Alen Castaño. Sibundoy. 2009.

\section{La aprobación de la iglesia}

Al ingresar al pueblo, todos los participantes del carnaval deben asistir a misa. Mediante una eucaristía, el sacerdote municipal da el aval para iniciar con las actividades suscitadas en el castillo. Luego de recibir el permiso de inicio en la misa, el matachín lidera el desfile hacia el convento del pueblo, visita al obispo y realiza el ritual del perdón con los pétalos de las rosas en la cabeza del obispo (Figura 7). Evidenciando así la manera cómo la iglesia católica asume cierto control sobre esta festividad indígena al dar apertura al carnaval mediante la eucaristía (Sandoval Zapata y Lasso Otaya, 2014). 


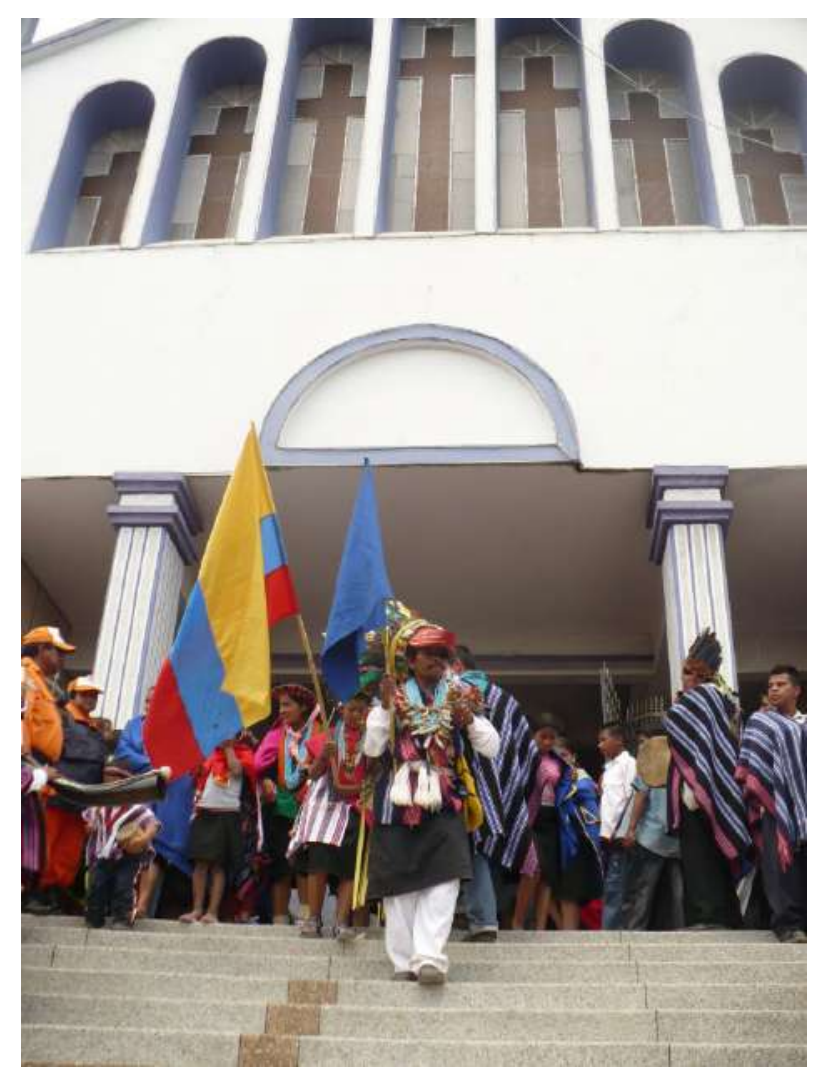

Figura 7. El Carnaval y la Iglesia.

Fuente: Fotografía de Alen Castaño. Sibundoy. 2009.

Luego de visitar al obispo y tener su respectiva aceptación, el Matachín lidera el desfile hacia una cruz que queda en el parque central del pueblo (para este caso, el parque es en el pueblo de Sibundoy). En ese momento se realiza el ritual de las banderas. Aquí los bandereros, personajes importantes para la comunidad como los gobernadores, comisarios mayores, taitas, etc., realizan una danza circular con las banderas alrededor de la cruz.

Al culminar esta ceremonia de banderas, el desfile se dirige hacia la alcaldía, bailan a las afueras de esta institución como protocolo de aceptación por parte del sistema occidental en el que viven las comunidades étnicas que residen en este valle, para que finalmente puedan ir al cabildo indígena. En este lugar el gobernador Camëtsa se ubica en la mesa principal con sus respectivos alguaciles. 


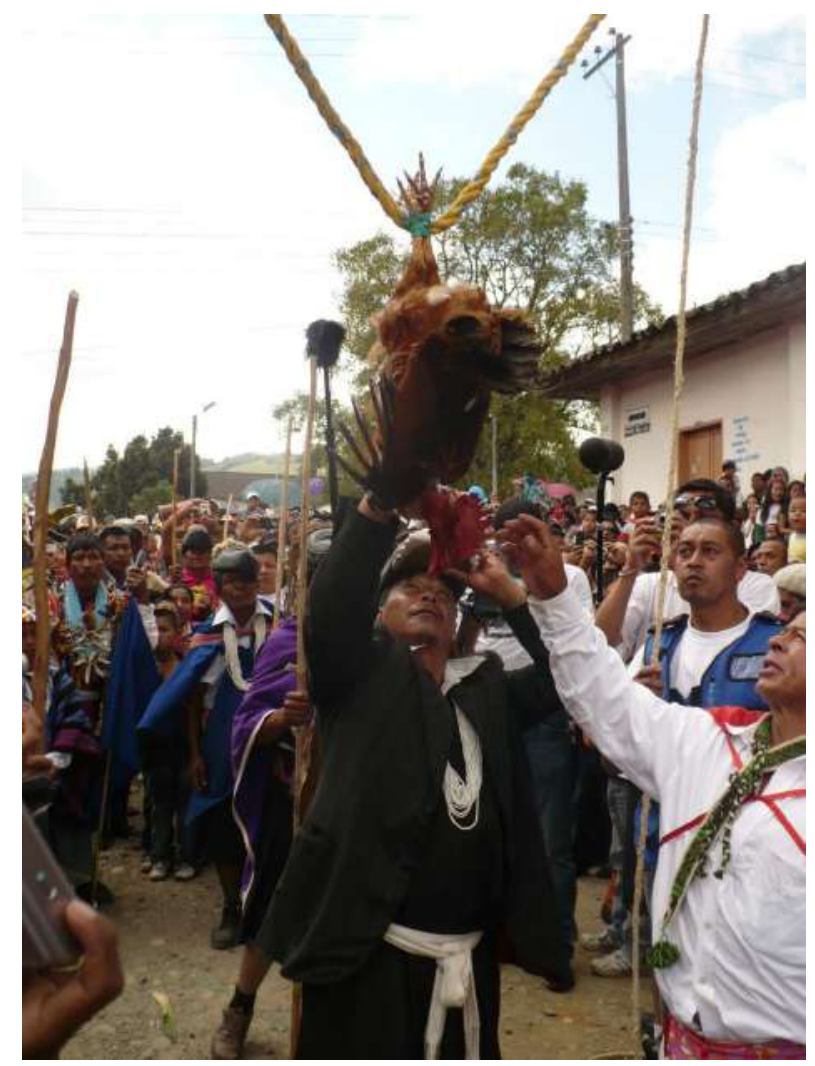

Figura 8. El gallo.

Fuente: Fotografía de Alen Castaño. Sibundoy. 2009.

El desfile finaliza en el castillo es el lugar donde se realiza el sacrificio de un gallo mediante un proceso de degollamiento (Figura 8). Este animal es amarrado boca abajo y amarrado de las patas para que un grupo de personas ubicadas en la parte trasera del castillo se encarguen de halarlo al momento que los Sanjuanes saltan a cogerlo (Figura 9).

Este procedimiento es repetitivo hasta que algún Sanjuán lo coja el cuello y con su propia fuerza pueda arrancarle el pescuezo. En ese momento se realiza una batalla mortal y de resistencia entre el Sanjuán y el gallo. Cuando el primero vence al segundo, el cabeza es amarrada en la punta de una lanza que tienen los Sanjuanes (que es utilizada para coger impulso al momento del salto) como símbolo de un trofeo (Figura 10). 


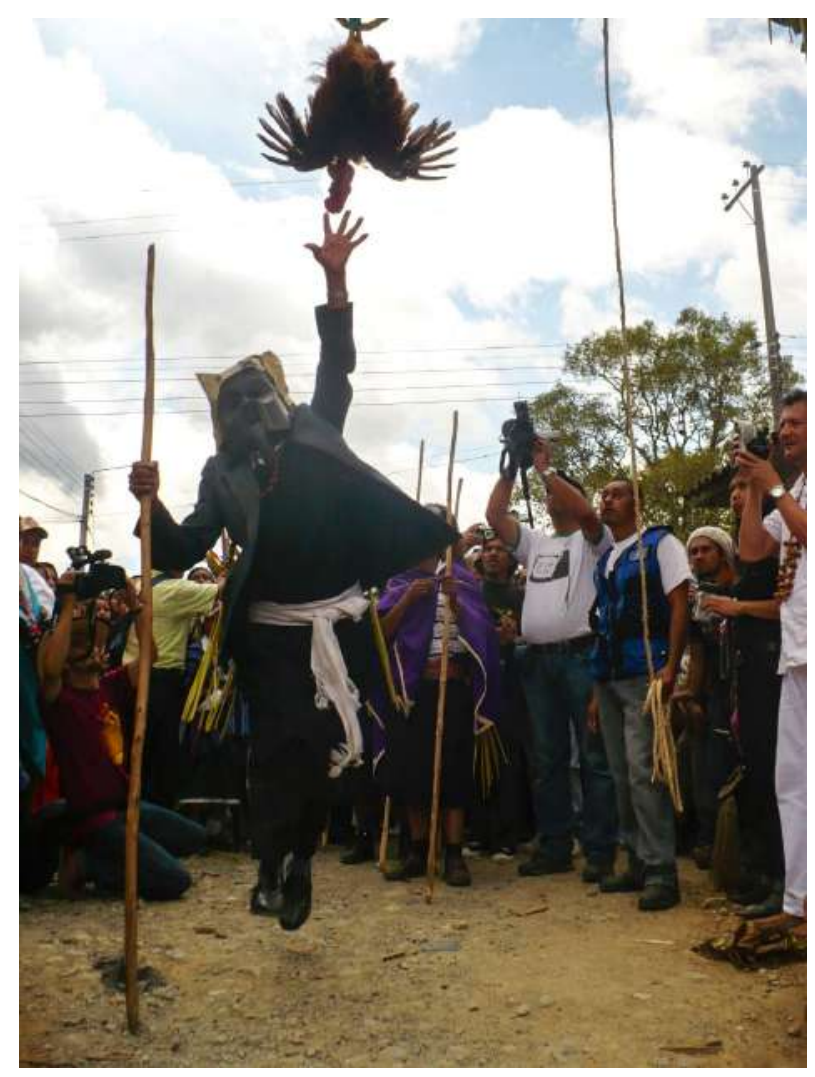

Figura 9. La pelea por el tiempo.

Fuente: Fotografía de Alen Castaño. Sibundoy. 2009.

Se comenta en la comunidad que los curas, al observar tal actividad, fue concebida como un ritual que tenía gran relación a lo sucedido con San Juan Bautista, el cual fue decapitado y su cabeza fue enviada en una bandeja de plata a Herodes (Gómez Montañez, 2017). Dada esta correlación, se le denominó a los saltantes del carnaval como Sanjuanes. 


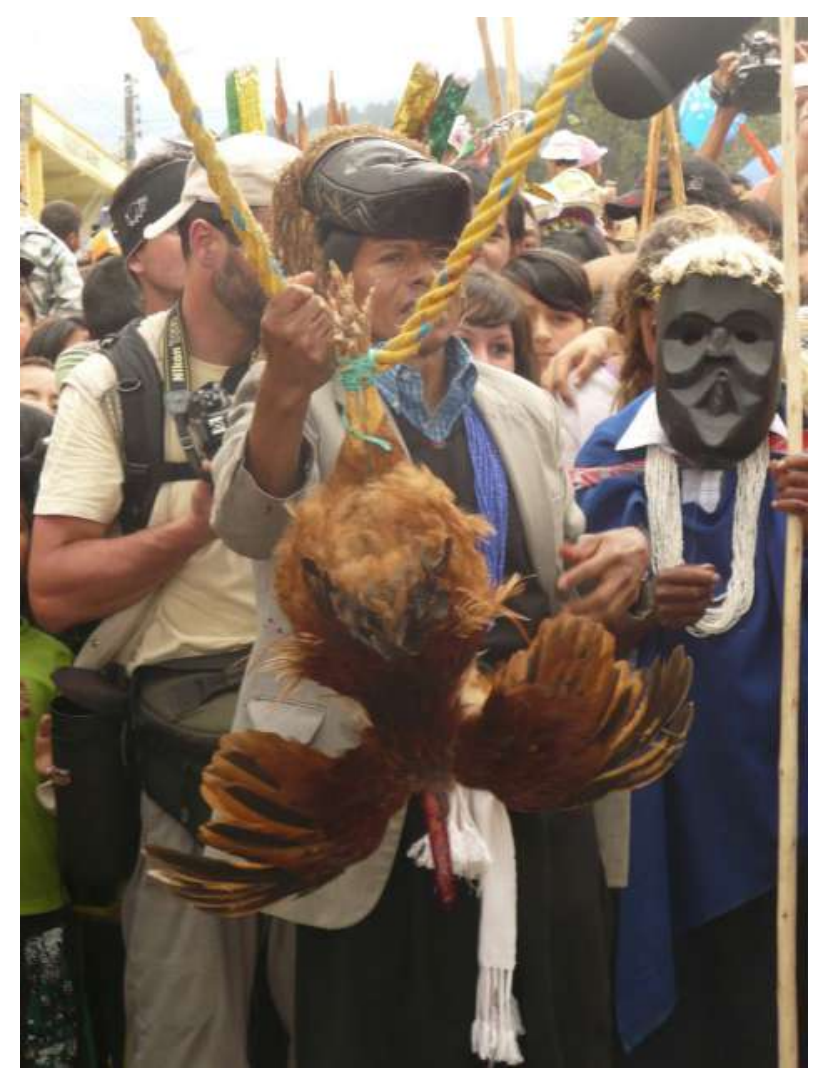

Figura 10. El inicio del nuevo año.

Fuente: Fotografía de Alen Castaño. Sibundoy. 2009.

\section{Las mil y una caras del Sanjuán}

Para algunos indígenas Camëtsa e Ingas, la interacción entre el Sanjuán y el gallo representa ese mundo occidental que martirizaban los indígenas sibundoyes en la época colonial y republicana (Figura 11). Dado lo anterior, se argumenta que la implementación de máscaras "horrorosas" por parte de los Sanjuanes, se da como una representación de las comunidades indígenas de la época que eran sacrificadas por el mundo occidental. Por lo tanto, los Sanjuanes usan máscaras con distintas fisionomías, ilustrando signos de tristeza y terror (Sandoval Zapata y Lasso Otaya, 2014). 


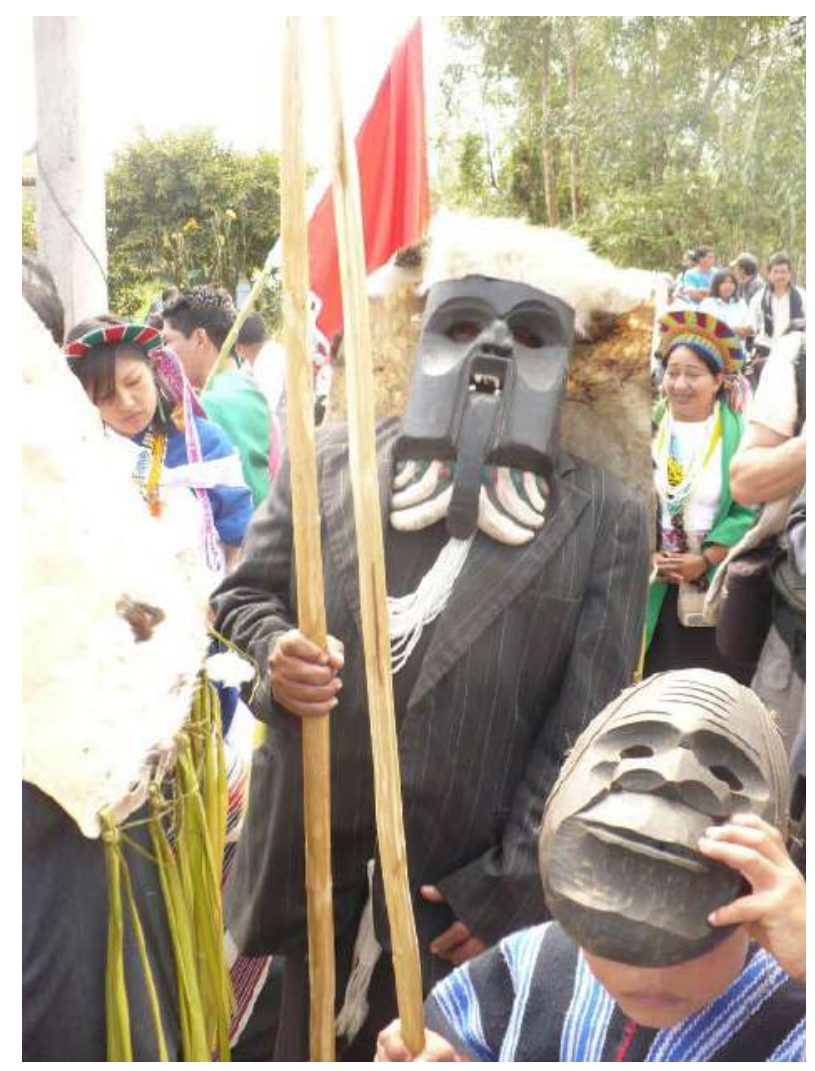

Figura 11. El Sanjuán.

Fuente: Fotografía de Alen Castaño. Sibundoy. 2009.

Por otra parte, el Sanjuán también representa un personaje burlón y pícaro, desde sus inicios le hacía muecas a los colonos, utilizando sus trajes tradicionales, como era el caso de los zapatos de material, pantalón, camisa, saco de corbata y una muñeca rubia en un canasto (como una representación de acceso a los niños occidentales) (Sandoval Zapata y Lasso Otaya, 2014) (Figura 12). 


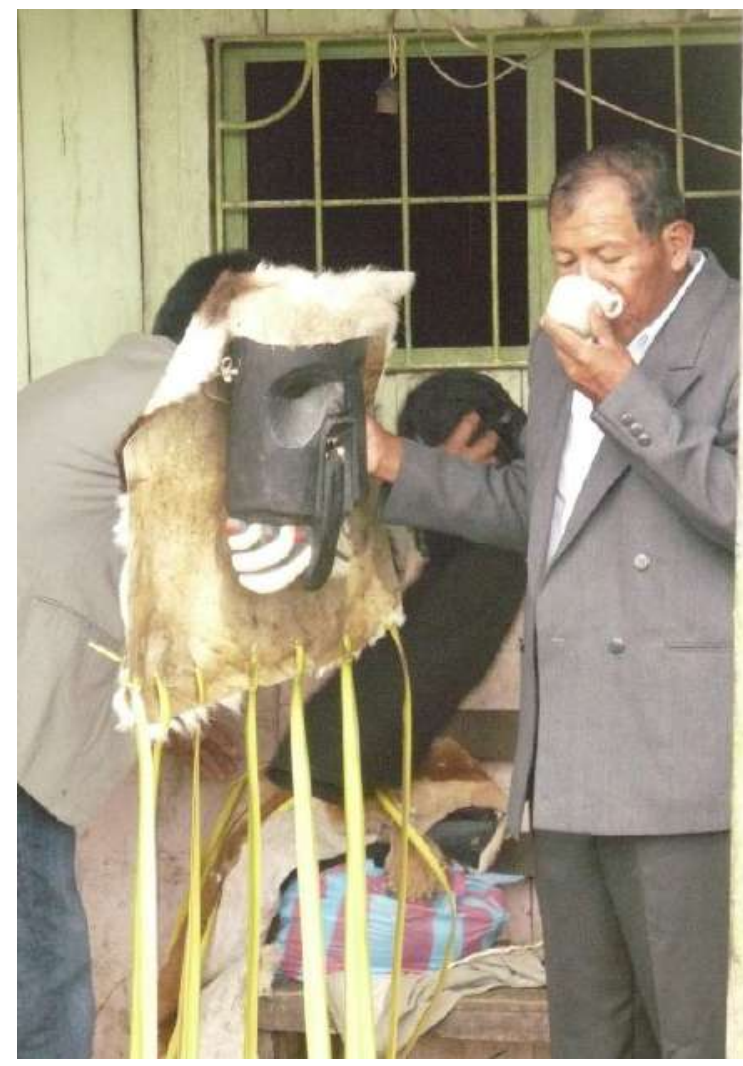

Figura 12. Preparación del Sanjuán.

Fuente: Fotografía de Alen Castaño. Sibundoy. 2009.

De este modo, la máscara del Sanjuán es la abstracción histórica referente a los diferentes atropellos cometidos por la iglesia en este territorio contra las comunidades indígenas, consolidándose como un elemento de gran carga y representación simbólica al interior de este carnaval. Cuentan los mayores Camëtsa que la máscara del Sanjuán es negra y con la lengua salida como expresión de aquellos antepasados que, ante la imposibilidad de realizar alguna acción contra la iglesia cuando sus representantes atentaban contra la integridad de la comunidad (abusos, violaciones, despojos y maltratos), éstos decidían ahorcarse (Fajardo, 2006). Es decir, la máscara hace alusión al cuerpo de cada indígena que era encontrado ahorcado, morado y con la lengua afuera al no tener las capacidades y herramientas necesarias para afrontar una institución tan fuerte en esa época como era la iglesia (Figura 13). 


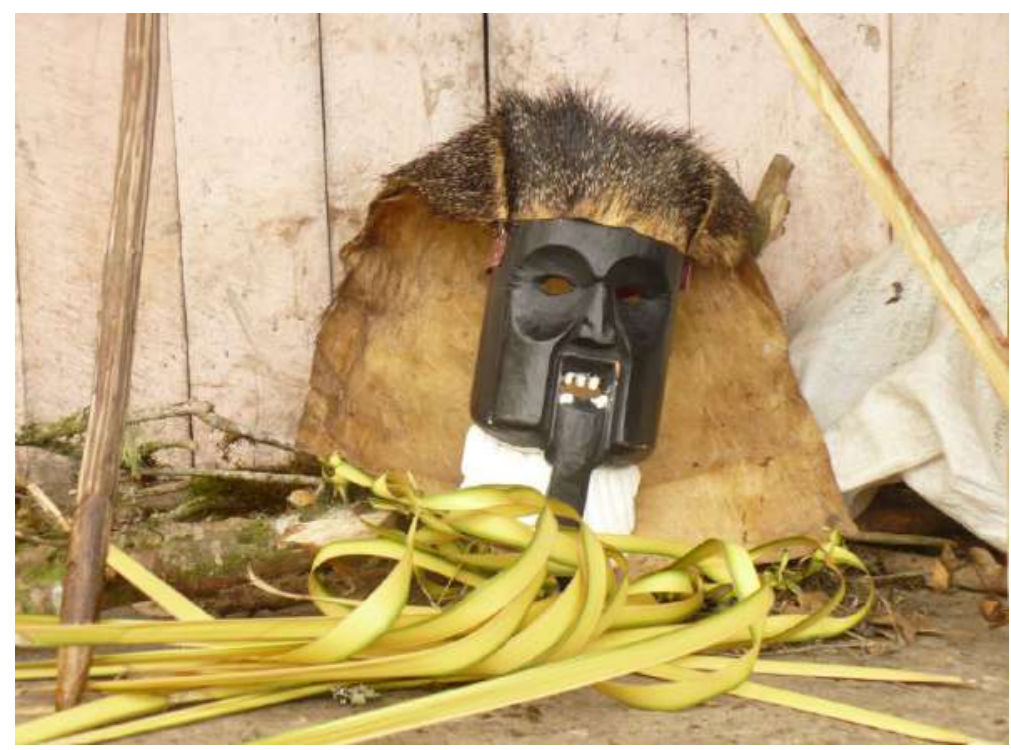

Figura 13. La máscara del Sanjuán.

Fuente: Fotografía de Alen Castaño. Sibundoy. 2009.

\section{Redondeando}

Como se pudo observar a lo largo de este material investigativo, la propuesta central del presente ensayo visual fue registrar una manifestación cultural realizada por las comunidades indígenas Inga y Camëtsa en el Valle de Sibundoy. Al tratar de evidenciar aquellos elementos que representan cierto sincretismo simbólico entre paradigmas indígenas y religiosos a través de diversas imágenes, el análisis y el sentir de la representación de este carnaval se basa en experiencias etnográficas dadas por las diversas idas y venidas a esta región del sur del país.

No se quiere con esto llegar a máximas o generalidades contundentes sobre lo que es o no el carnaval, sino que, por el contrario, ser una pequeña contribución, en este caso fotográfico, de una de las múltiples formas de poder observar e interpretar la importancia de este ritual. Por tal motivo, se reconocen las falencias analíticas e investigativas que pueda tener esta propuesta visual, pero el énfasis aquí reside en poder visibilizar los elementos, las partes y la simbiosis de dos mundos que por causas fortuitas o no, se vieron entrelazados por la historia del norte del putumayo. 


\section{Referencias bibliográficas}

Bonilla, V. D. (1968). Siervos de Dios y Amos de Indios; el Estado y la misión capuchina en el Putumayo. Ediciones Tercer Mundo.

Colombia. Ministerio de Cultura. Resolución n. 3471 de 2013. Por la cual se incluye la manifestación "Bëtscnaté, o Día Grande de la tradición camëtsa", en la Lista representativa de patrimonio cultural inmaterial del ámbito nacional y se aprueba su Plan Especial de Salvaguarda.

Fajardo, J. (2006). El Carnaval del Perdón. Revista Porik An, (11), 399-416. http://www. unicauca.edu.co/porik_an/imagenes_3noanteriores/No.11porikan/articulo12.pdf

Gómez Montañez, P. F. (2020). El Carnaval del Perdón de Sibundoy, Colombia. Armonización, conectividad y comunicación para la paz. Athenea Digital: revista de pensamiento $e$ investigación social. 20(3), 1-22. https://doi.org/10.5565/rev/athenea.2440

Jaramillo Guerrero, J. y Dávila Zambrano, L. (2013). Estéticas convergentes. Sincretismo cultural en el Bëtscnaté Kamëtsa Biÿa de Sibundpy Putumayo (Tesis de maestría). Universidad de Nariño, Pasto, Colombia.

Pulido Ángel, O. J. (2015). Etnicidad y religiosidad en el pueblo Inga del valle de Sibundoy (Tesis de Maestría). Universidad Pedagógica Nacional, Bogotá, Colombia.

Sandoval Zapata, K. y Lasso Otaya, H. (2014). Evangelización, encubrimiento y resistencia indígena en el Valle de Sibundoy Putumayo. Revista Historia y Espacio, 10(43), 1-25. https://doi.org/10.25100/hye.v10i43.1208 